\title{
An analysis of experimental fishing traps in the coastal area of the United Arab Emirates
}

\author{
Elsayed Farrag, Ahmed Al-Zaabi and Romina L. Nuqui \\ DOI: $10.29322 /$ IJSRP.10.10.2020.p10663 \\ http://dx.doi.org/10.29322/IJSRP.10.10.2020.p10663
}

Marine Environment Research Department, Ministry of Climate Change and Environment, UAE

\begin{abstract}
The fisheries of the United Arab Emirates are considered as a traditional fisheries and provide a source of income, employment and recreation. With the advancement of marine industries, fisheries are a major source of food security. The main fishing gear in the United Arab Emirates is a dome-shaped wire trap. Despite the economic important of the traps on the Arabian Gulf, scatter studies dealt with this fishing gear. The present study investigates the effect of trap size, season, trap soak time on the catch rate. Catch composition and trap loss rates were studied from March 2015 to February 2016. From 601 trap hauls weighed 2213.0kg for an average of $3.68 \mathrm{kgs} /$ trap/pull, catches were comprised of 47 species in which 18 were primary commercial species, 16 were secondary commercial fish species and 13 are by-catch fish species. Average catch for primary, secondary commercial species were 6.80 and $3.34 \mathrm{~kg} / \mathrm{trap} / \mathrm{haul}$ respectively. On the other hand, the average of by-catch was $0.92 \mathrm{~kg} /$ trap/haul for all trap sizes. Catch rate from the different trap sizes showed that, the trap with the diameter of $2.8 \mathrm{~m}$ had the highest overall catch rate as well as the primary commercial species and contribute $37.04 \%$ of the catch rates for different trap sizes. Traps of $2.08 \mathrm{~m}$ and $3.3 \mathrm{~m}$ of diameter had the second and third highest overall catch rates and contribute $36.41 \%$ and $15.88 \%$ respectively. ANOVA results showed a significant difference $(\mathrm{P}<0.01)$ between catch rates of different size traps for primary, secondary and by-catch. In the present study, there was not relationship found between trap soak time and catch rate. It's mean meaning the catch rate not increase with increasing soak time. The present study recommended to use medium and large trap sizes and avoid using of small trap.
\end{abstract}

Index Terms- Trap, catch composition, species composition, Arabian Gulf, soak time.

\section{INTRODUCTION}

$\mathrm{T}$ The fisheries of the United Arab Emirates are small-scale in nature, with the vast majority taking place in the Emirate of Abu Dhabi, which is reported to comprise over $60 \%$ of the country's marine area ${ }^{[1]}$. Fishers employ two distinct fishing vessel types: fiberglass tarrads (speed boat) and traditional wooden dhows (lanch). Tarrads are typically 6-8m in length and equipped with 1-2 outboard engines, allowing a crew of 1-4 people to fish for 6-8 hours at a time ${ }^{[2]}$. Dhows, on the other hand, range from 12- $22 \mathrm{~m}$ and are equipped with inboard diesel engines and insulated cool boxes, allowing the crew of 4-6 people to fish for 3-5 days at a time. The UAE's fisheries are multi-gear and multispecies, with over 100 species occurring in the catch ${ }^{[3]}$. The main fishing gear is a dome-shaped wire trap called gargoor, hand lines, intertidal weirs (hadrah), trolling, gillnets, and encircling nets are also used ${ }^{[4]}$. Trap, gargoor is a traditional demersal fishing gear, which was in the past made of palm leaves woven into a semi-circular shape, where fish bait is placed inside to attract fish and changed over-time to galvanized steel wire. The diameter of the trap base varies between 1 and $3 \mathrm{~m}$, they are supported by tubular steel bars and have a funnel entrance. Most fish species caught by traps belong to the families Serranidae, Lethrinidae, Lutjanidae, Haemulidae, Carangidae and Mugilidae. Though fisheries are of minor importance to the UAE's economy, they are valued for the recreational opportunities they provide, for their contributions to food security, and as a part of the country's cultural heritage. The present study aims to evaluate and analyze of the experimental trap fishery in the sea area of the UAE, catch analysis (catch composition, identification and quantity), catch per unit effort (CPUE) and the impact of soak time on the fisheries.

\section{MATERIALS AND METHODS}

\section{A. Study Area and Period}

The traps were deployed in three different locations within the UAE's fishing ground, the first location with the Latitude of $25^{\circ} 37.303^{\prime} \mathrm{N}$, Longitude of $55^{\circ} 34.639^{\prime} \mathrm{E}$, second location with Latitude $25^{\circ} 36.793^{\prime} \mathrm{N}$, Longitude of $55^{\circ} 34.281^{\prime} \mathrm{E}$ and third location with Latitude of $25^{\circ} 36.254^{\prime}$ N, Longitude of 55³4.246’E Fig. 1. The study started from March 2015 to February 2016. 


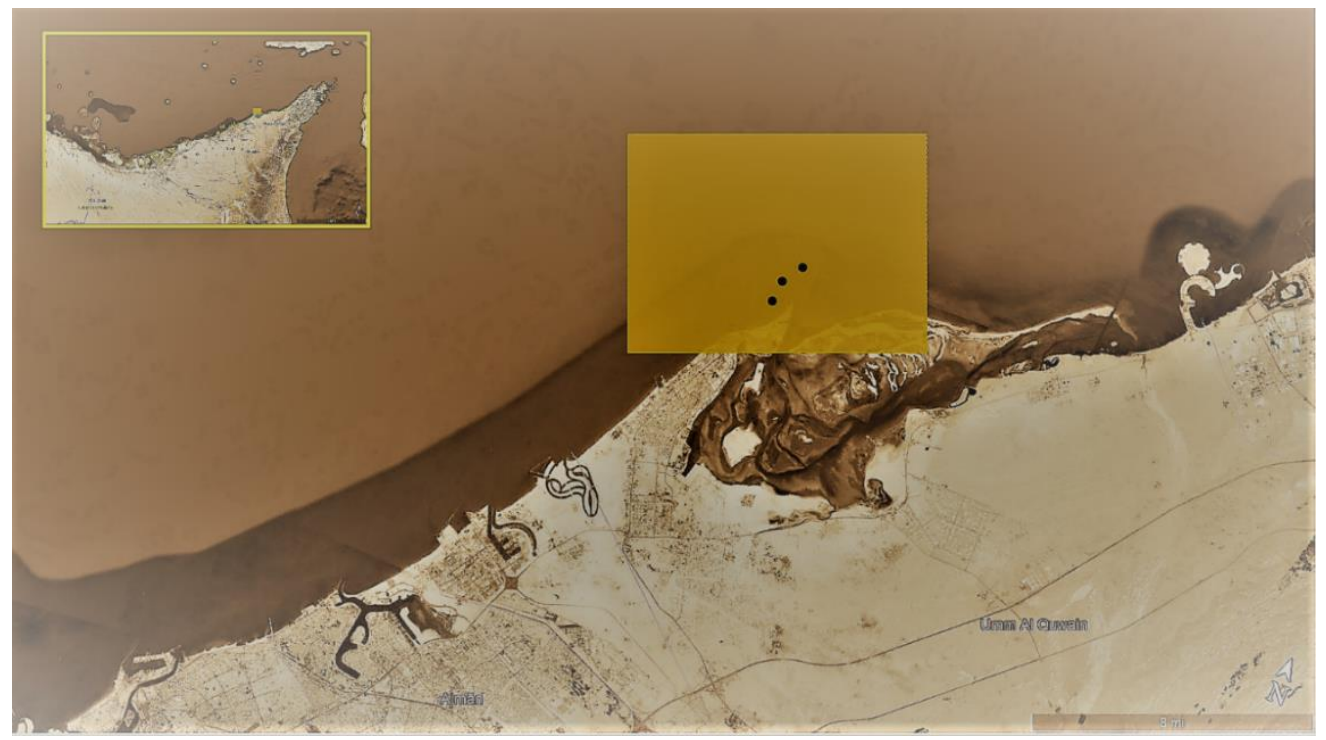

Figure 1. Map of the United Arab Emirates showing the experimental locations

\section{B. Experimental Design and deployment}

The field experiment covered at least one full year to study the seasonal variation in the catch rate and species composition of the fish trap fishery. The most common trap size in UAE's fishery is a trap with a base of $143 \mathrm{~cm}$, however, the fishermen also used other sizes of traps. These trap sizes were tested to consider if different trap sizes would result different catch rates and species composition. The experimental trap used are four different sizes, Extra Large (with base length of $190 \mathrm{~cm}$, height of $103 \mathrm{~cm}$, diameter of $330 \mathrm{~cm}$, panel length and width of $75 \mathrm{~cm}$ ), Large (with base length of $176 \mathrm{~cm}$, height of $81 \mathrm{~cm}$, diameter of $280 \mathrm{~cm}$, panel length and width of $60 \mathrm{~cm}$ ), Medium (with base length of $143 \mathrm{~cm}$, height of $64 \mathrm{~cm}$, diameter of $208 \mathrm{~cm}$, panel length and width of $45 \mathrm{~cm}$ ), and Small (with base length of $93 \mathrm{~cm}$, height of $45 \mathrm{~cm}$, diameter of $150 \mathrm{~cm}$, panel length and width of $75 \mathrm{~cm})$. Numbered plastic plates was attached to each trap. The traps position was recorded using Global Position System (GPS) but were not marked by buoys to avoid poaching from other fishermen. Sets of four different sizes were deployed on each location.

\section{Sampling Procedure}

Traps were monitored twice weekly and sometimes more than two times due to weather condition and in some cases of traps lost. The trap soak time was between 2 to 4 days and during the experiment the number of soaking time reach to 15 days to check the relationships between catch rate and soak time and between trap loss and soak time. The catch from each trap was sorted, identified and subsamples were taken to measure total, forked lengths and total, gutted weights. The species identification followed the methods of Carpenter et al. 1997 and Forese \&Pauly, $2008^{[5 \& 6]}$.

\section{Data Analysis}

Catch data were analyzed and grouped by month, catch size, the pulled traps, and catches were grouped into primary commercial fish, secondary commercial fish, and by-catch. The primary commercial fish that species are popular and has high market value. Secondary commercial species are marketable but has lower value. By-catch are fishes not common and has the lowest value and sometimes returned to the sea. The catch rates for different species categories and of different sizes were obtained similarly and tested with analyses of variance ANOVA for significant difference.

\section{RESULTS AND DISCUSSION}

\section{A. Traps Catch Analysis}

Table I shows the species composition from 601 trap hauls weighed $2213.0 \mathrm{~kg}$ for an average of $3.68 \mathrm{kgs} / \mathrm{trap} / \mathrm{pull}$, catches were comprised of 47 species in which 18 were primary commercial species, 16 were secondary commercials fish species and 13 are by-catch fish species. From the total catch, $1361.38 \mathrm{~kg}(61.52 \%)$ were primary commercial species, comprised of (greatest to least order). $667.672 \mathrm{~kg}(30.17 \%)$ were composed of secondary fish species and $183.96 \mathrm{~kg}(8.31 \%)$ from the total catch were monitored as a by-catch. The primary commercial species was dominated by E. coioides and represent $10.09 \%$, followed by L. nebulosus and S. canaliculatus by $7.60 \%$ and $6.82 \%$ respectively. The dominant catch for secondary commercial belongs to Sepia sp. and Scarus persicus and represent 
$4.63 \%$ and $3.82 \%$ respectively. While Platax orbicularis contribute $2.0 \%$ and was dominant in by-catch. The catch composition of the trap in Saudi territorial waters of the Arabian Gulf was studied and the results declared that ${ }^{[7]}$, all species caught by trap are belong to 10 major families and the dominant families were Lethrinidae, Carangidae and Serranidae (23.95\%, $18.7 \%$ and $15.5 \%$ respectively. He stated also that, the catch composition was the same in both large and small boats and the only difference was in fish size and quantity. On the northern part of the Arabian Gulf, Chen et al, 2012 ${ }^{[8]}$ stated that from 1745 trap hauls weighed $7840 \mathrm{~kg}$, for an average $4.5 \mathrm{Kg} / \mathrm{trap} / \mathrm{haul}$ (ranging from 2.45 to $7.97 \mathrm{~kg}$ ) and the catches were comprised of 70 species, the primary commercial species $(56.94 \%)$ dominated by Argyrops spinifer, Epinephelus coioides and Plectorhincus pictus and contribute 13\%, 12.24 and 6.83\%. Secondary commercial species (34.52\%), of which seven species contributed $30.25 \%$ and the Netuma bilineatus and Pomadasys stridens constitute $8.83 \%$ and $7.0 \%$ respectively. The study also revealed that, the average catch rate of trap has been declining since 1991 Gulf War. The average catch rate from 1980 through 1989 was $5.8 \mathrm{~kg}$ per trap ranging from $2.8 \mathrm{~kg}$ to $11.0 \mathrm{~kg}{ }^{[9]}$. The average catch rate of trap was estimated by ${ }^{[10]}$ as $3.57 \mathrm{~kg} / \mathrm{trap} / \mathrm{haul}$ and mentioned that Lethrinus spp was ranked first by $15.5 \%$ and E. coioides accounted $14.8 \%$.

Table I. Species composition of the total catch from the experimental traps.

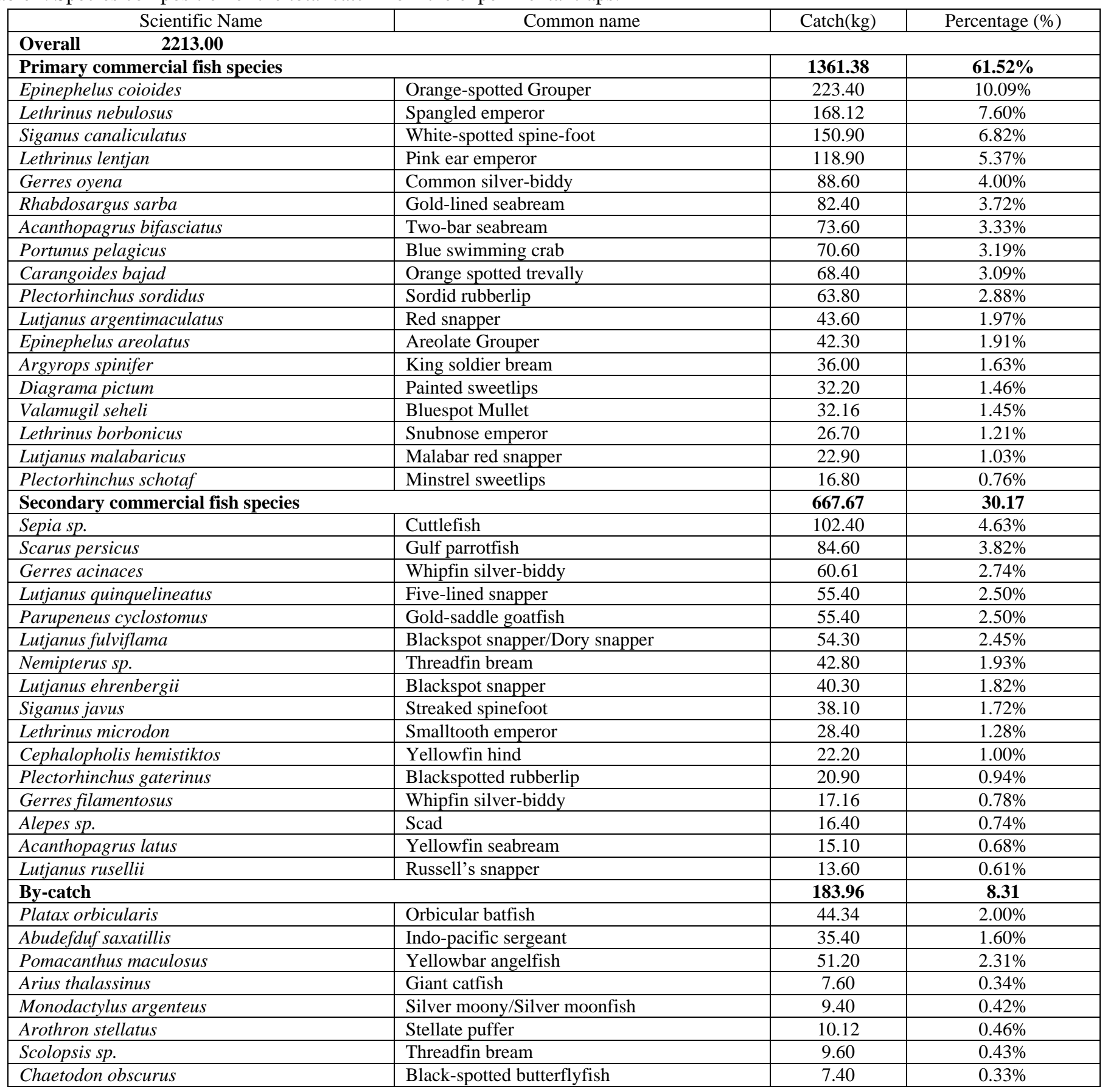

This publication is licensed under Creative Commons Attribution CC BY. 


\begin{tabular}{|l|l|c|c|}
\hline Terapon jarbua & Jarbua terapon & 3.20 & $0.14 \%$ \\
\hline Amblygobius albimaculatus & Butterfly goby & 0.90 & $0.04 \%$ \\
\hline Alutea monoceros & Unicorn leatherjacket filefish & 0.20 & $0.01 \%$ \\
\hline Platycephalus indicus & Bartail flathead & 1.20 & $0.05 \%$ \\
\hline Aphanius dispar & Arabian pupfish & 3.40 & $0.15 \%$ \\
\hline
\end{tabular}

\section{B. Catch Per Unit Effort}

The average monthly catch per unit effort as ( $\mathrm{kg} / \mathrm{trap} / \mathrm{haul})$ for different species categories was obtained and the results declared that, the average catch for primary species was $6.80 \mathrm{~kg} /$ trap/haul, while the average catch for secondary commercial species was $3.34 \mathrm{~kg} / \mathrm{trap} / \mathrm{haul}$. On the other hand, the average of by-catch was $0.92 \mathrm{~kg} / \mathrm{trap} / \mathrm{haul}$ for all trap sizes. Table II shows the catch seasonality for primary, secondary and by-catch. It is obvious that the catch per unit effort for overall species reach to maximum catch during spring (7.83, 4.26 and $1.14 \mathrm{~kg} / \mathrm{trap} / \mathrm{haul}$ respectively). In general, the mean CPUE for primary species constitute the highest rate $6.80 \mathrm{~kg} / \mathrm{trap} / \mathrm{haul}$ then followed by secondary and by-catch by 3.34 and $0.92 \mathrm{~kg} /$ trap/haul respectively. This is probably related to fish spawning, feeding behavior and change of water temperature. The period from March to May are the main spawning seasons for most of the commercial species. Fishes such as L. nebulosus and E. coioides aggregate in open water for spawning. In summer, water temperature exceeds $32^{\circ} \mathrm{C}$ and fishes then move to deep water to avoid the high water temperature. In the territorial Saudi waters ${ }^{[7]}$ the CPUE sharply decreased for both large and small traps during Winter season (7.7 and $2.3 \mathrm{~kg} / \mathrm{trap}$, respectively). The study indicated also that, the average catch/fishing day relatively fluctuated in the large boats during the years, while it tended to increase in small boats. In addition, it can be noticed from the trips observations that the loss percentage of traps was higher in large boats (about 12\%) than in small boats (about 8\%), this may be due to the different ecological factors including water moving in deeper and shallow waters of the fishing areas. Chen $e t a l,{ }^{[8]}$ showed seasonal changes, the monthly catch rates were high $(>6 \mathrm{kh} / \mathrm{trap} / \mathrm{haul})$ from April through July and in December, while the low catch rate (2-5kh/trap/haul) was recorded in August through October and from February through March. Shabani et al, ${ }^{[11]}$ recorded a similar peak of catch rate (3.9kg/trap-month) in May for the trap along the East side of the Arabian Gulf.

Table II. Catch seasonality (kg/trap/haul) for the primary, secondary and by-catch caught by different trap sizes.

\begin{tabular}{|l|c|c|c|c|}
\hline Season & Primary & Secondary & By-catch & Mean \\
\hline Winter & 7.79 & 3.92 & 0.67 & 4.13 \\
\hline Spring & 7.83 & 4.26 & 1.14 & 4.41 \\
\hline Summer & 5.97 & 2.37 & 0.88 & 3.07 \\
\hline Autumn & 5.62 & 2.83 & 0.98 & 3.14 \\
\hline Mean & 6.80 & 3.34 & 0.92 & \\
\hline
\end{tabular}

\section{Catch Rate by Trap Size}

Catch rate from the different trap sizes showed that, the trap with the diameter of $2.8 \mathrm{~m}$ had the highest overall catch rate as well as the primary commercial species and contribute $37.04 \%$ of the catch rates for different trap sizes. Traps of $2.08 \mathrm{~m}$ and $3.3 \mathrm{~m}$ of diameter had the second and third highest overall catch rates and contribute $36.41 \%$ and $15.88 \%$ respectively. ANOVA results showed a significant difference $(\mathrm{P}<0.01)$ between catch rates of different size traps for primary, secondary commercial catch and by-catch. On the other hand, trap size $1.5 \mathrm{~m}$ diameter had significant lower catch rates of overall, primary, secondary commercial species and a highly significant difference in by-catch compared with the trap size $2.8 \mathrm{~m}$ diameter. The catch rates of different trap sizes are shown in table III. Basically the traps of $2.8 \mathrm{~m}$ and $2.05 \mathrm{~m}$ in diameter had a significant higher overall catch rate as well as that of primary and secondary commercial fish. In Kuwait's water, Chen et al, ${ }^{[8]}$ declared that, the highest overall catch rate as well as the primary species were not result from the largest diameter $2.25 \mathrm{~m}$ but from the second largest size $2.15 \mathrm{~m}$ and the study recommended the trap size $2.15 \mathrm{~m}$ in diameter is appropriate size for Kuwait's trap fishery. The study also declared that, large size trap has more space within a trap and will be less affected by capture fish density especially when soak time is long.

Table III. Catch rate $(\mathrm{kg})$ of different trap sizes

\begin{tabular}{|l|c|c|c|c|c|c|c|}
\hline Trap Size & Total Trap Haul & Overall & Primary & Secondary & By-catch & Mean & \% \\
\hline 3.3 & 68 & 430.70 & 98.4 & 58.9 & 27.63 & 61.64 & 15.88 \\
\hline 2.8 & 79 & 761.70 & 229.5 & 79.4 & 11.32 & 106.74 & 37.04 \\
\hline 2.08 & 62 & 736.80 & 225.63 & 125.32 & 43.82 & 131.59 & 36.41 \\
\hline 1.5 & 58 & 283.80 & 66.08 & 36.2 & 45.8 & 49.36 & 10.66 \\
\hline No. & $\mathbf{2 6 7}$ & & & & & & \\
\hline Overall & & $\mathbf{2 2 1 3 . 0}$ & & & & & \\
\hline Mean & & $\mathbf{1 5 4 . 9 0}$ & $\mathbf{7 4 . 9 6}$ & $\mathbf{7 7 . 9 9}$ & & \\
\hline
\end{tabular}


The average size (total length in centimeters and weight in grams) of fish caught from the different trap sizes showed that, the trap size $2.80 \mathrm{~m}$ diameter, caught fish with an average length and weight $(33.0 \mathrm{~cm}$ and $413.0 \mathrm{~g})$, while the larger trap caught fish with an average length and weight $(31.0 \mathrm{~cm}$ and $388.0 \mathrm{gm})$ Table IV. The study conducted by Tharwat and Al-Gaber ${ }^{[7]}$ in Saudi Arabia, found that larger traps captured larger individuals due to the larger individual sizes to location (deeper waters) and larger opening of the entrance funnel. This would indicate that escape rings should be a solution to sizes election. Escape rings can be incorporated into the construction of the trap to reduce catches of undersized species. Being a multi-species gear, however, presents challenges whose solutions are not straightforward. Target species are not necessarily similar in shape, and because they mature at different ages (i.e., sizes), effort to select one size might be at the expense of other target species ${ }^{[10]}$. The study recommended that only the larger and medium sized traps be legal and the small traps with small opening funnel and mesh size have a passive effect on the reproductive cycle of many fish species, that they catch large number of immature fishes. Therefore, it could be recommended to operate the large and medium trap only while the small traps should be prohibited. The same results obtained by Chen et al. ${ }^{[8]}$ in Kuwait's water, the $2.15 \mathrm{~m}$ diameter captured large size fish that were only slightly smaller than those captured in the $2.25 \mathrm{~m}$ diameter.

Table IV. Size composition of combined fish caught by different trap sizes

\begin{tabular}{|l|c|c|c|c|}
\hline \multirow{2}{*}{ Parameters } & \multicolumn{4}{c|}{ Trap diameter (m) } \\
\cline { 2 - 5 } & $\mathbf{1 . 5 0}$ & $\mathbf{2 . 0 8}$ & $\mathbf{2 . 8 0}$ & $\mathbf{3 . 3 0}$ \\
\hline Average length $(\mathrm{cm})$ & 23.0 & 28.0 & 33.0 & 31.0 \\
\hline Average weight $(\mathrm{g})$ & 280.0 & 350.0 & 413.0 & 388.0 \\
\hline Number of fish & 345 & 1503 & 1135 & 980 \\
\hline
\end{tabular}

The percentage of species composition (\% in weight) of the most dominant species showed that, the traps with size $2.08 \mathrm{~m}$ and $2.8 \mathrm{~m}$ diameter had the same dominant species: E. coioides, L. nebulosus, L. quinquelineatus and G. oyena Table V. The dominant species of trap diameter $1.5 \mathrm{~m}$ is P. pelagicus. On the other hand, the dominant species of trap diameter 3.3 are L. nebulosus, L. quinquelineatus. In the territorial waters of Saudi Arabia ${ }^{[7]}$ obvious that emperors, sea breams, groupers, scads/jacks/ and trevallies, rabbit fishes, snapper and others (mainly crabs, Grunt, goatfish and bartail) were the common species in the catch. The different mesh sizes were not tested in this study and the common mesh size used by the local fishermen ranged from 40 to $50 \mathrm{~mm}$. Meanwhile, there were reports ${ }^{[11 \text { and } 12]}$ stated that larger mesh sizes (e.g. $55 \mathrm{~mm}$ and $70 \mathrm{~mm}$ ) had resulted in much higher percentage of fish scape ${ }^{[8]}$.

Table V. Species composition (\% in weight) for the catch caught by different trap sizes

\begin{tabular}{|l|c|c|c|c|c|}
\hline \multirow{2}{*}{ Species } & \multicolumn{5}{c|}{ Trap diameter } \\
\cline { 2 - 5 } & $\mathbf{1 . 5}$ & $\mathbf{2 . 0 8}$ & $\mathbf{2 . 8}$ & $\mathbf{3 . 3}$ & Mean \\
\hline Epinephelus coioides & 2.50 & 12.40 & 14.30 & 4.60 & 8.45 \\
\hline Lethrinus nebulosus & 4.50 & 8.60 & 7.90 & 6.30 & 6.83 \\
\hline Lutjanus quinquelineatus & 2.80 & 6.80 & 7.90 & 5.40 & 5.73 \\
\hline Gerres oyena & 4.30 & 8.90 & 5.30 & 3.20 & 5.43 \\
\hline Carangoides bajad & 3.50 & 5.40 & 6.80 & 4.90 & 5.15 \\
\hline Portunus pelagicus & 6.50 & 7.30 & 4.30 & 2.40 & 5.13 \\
\hline Siganus canaliculatus & 3.20 & 4.70 & 7.80 & 2.80 & 4.63 \\
\hline Scarus persicus & 4.50 & 6.40 & 5.20 & 2.10 & 4.55 \\
\hline Lethrinus lentjan & 1.20 & 6.70 & 5.40 & 4.80 & 4.53 \\
\hline Rhabdosargus sarba & 3.20 & 5.40 & 6.30 & 2.10 & 4.25 \\
\hline Lutjanus ehrenbergii & 3.40 & 6.50 & 3.20 & 3.00 & 4.03 \\
\hline Acanthopagrus bifasciatus & 2.30 & 5.40 & 4.80 & 3.20 & 3.93 \\
\hline Plectorhinchus sordidus & 2.30 & 3.60 & 4.50 & 4.00 & 3.60 \\
\hline
\end{tabular}

\section{Effect of soaking time on the catch rate}

In the present study, there was no relationship found between trap soak time and catch rate. It means the catch rate does not increase with increasing soak time. However, trap loss was positively co-related to soak time. The longest soak time in the current study is 15 days. Miller, $1983^{[13]}$ reported that, the catch rate usually increases with soak time to some asymptotic bound or increase with soak time to maximum value and thereafter decrease with longer soak time ${ }^{[14 \& 15]}$. Pengilly and Tracy $1998^{[16]}$ stated the catch rate decreased with increasing soak time over the range of 12-72h in commercial king crab pots. After a certain soak time, mean catch rate either approach a maximum value or decreases with increased soak time. The result revealed that the trap loss increased as the soak time increased, about $35 \%$ of the trap lost with increase soak time to 10 days. However, the percentage increased to $56 \%$ with increasing soak time to 15 days. In Saudi territorial waters of the Arabian Gulf ${ }^{[7]}$ found the estimated annual percentage of lost traps was higher for large boats 
than of small boats. In Kuwait's water the catch rate did not increase with the increase of the soak time and this result harmonized with the current study. About $88 \%$ of the trap were lost after 100 days if the traps are not cleared during this period. While $36 \%$ of the traps were lost after 100 days if the traps were cleared at 20 days' intervals ${ }^{[8]}$ and $60 \%$ of the trap lost due to lack of buoy. The present study explained the shorter soak time reduced the percentage of trap loss, although higher frequency of clearing trap will increase trap fishing effort and running cost. Mathew et al, $1987^{[17]}$ reported the financial losses due to ghost fishing reach 3\% - 13.5\% of the total catch value in the trap fishery in Kuwait. In the Sea of Oman, the mortality could be as high as 78.36kg/trap in the 6-month period after a trap being deployed in water ${ }^{[18]}$. The present study recommended that to reduce loss of trap the soaking time not exceeding 7 days.

\section{CONCLUSION}

The fisheries in the UAE are small-scale, with catches increasing until 1999, after which started to decline. The main fishing gear is a dome-shaped wire trap called a gargoor. The present study describes and evaluate the catch and species composition caught by different sizes of the traps. The present study declared that small size of the trap should be avoid because the low catch rates and smaller average sizes of the catch. Soak time less than 10 days increase the catch rate and decrease the trap lost. Therefore, it could be recommended to operate the large and medium traps only while the small traps should be prohibited.

\section{REFERENCES}

[1] G. Morgan, "Country review: United Arab Emirates. In: De Young C (ed.), Review of the state of world marine capture fisheries management:Indian Ocean, FAO Fisheries Technical Paper 488. Food and Agriculture Organization of the United Nations (FAO), Rome, 2004. pp. 327-335

[2] D. Al-Abdulrazzak,"Estimating total fish extractions in the United Arab Emirates:1950-2010. Pp. 53-59. In: D. Al-Abdulrazzak and D. Pauly (eds.) From dhows to trawlers: a recent history of fisheries in the Gulf countries, 1950-2010. Fisheries Centre Research Reports 21(2), Fishereies Centre, University of British Columbia [ISSN 1198-6727].

[3] E. Grandcourt, TZ Al Abdessalaam, F. Francis and A. Al shamsi, Age-based life history parametes and status assessments of bycatch species(Lethrinus brobonicus, Lethrinus microdon, Pomacanthus maculosus and Scolopsis taeniatus) in the southern Arabian Gulf,". Journal of Applied Ichthyology. 2010;26 (3):381-389

[4] E. Grandcourt, F. Francis, A. Al-Shamsi, K. Al-Ali and S. Al-Ali, "Annual fisheries statistics for Abu Dhabi Emirate 2001," Marine Environmental Research Center, Abu Dhabi, UAE, 2002, p.94.

[5] K.E. Carpenter, F. Krupp, D.A. Jones, and U.Zajonz, FAO Species Identification Guide for Fishery Purposes, Living Marine Resources of Kuwait, Eastern Saudi Arabia, Bahrain, Qatar, and the United Arab Emirates. Food and Agriculture Organization of the United Nations, Rome, Italy.1997

[6] R. Forese, D. Pauly (eds.): Fishbase. World Wide Web electronic publication. http://www.fishbase.org, version (7/2008).

[7] A. A.Tharwat and A. R. Al-Gaber. Fishery Traps (Gargours) in Saudi Territorial Waters of the Arabian Gulf. JKAU Marine Sciences. 2006; 17:13-31. https://doi.org/10.4197/mar.17-1.2

[8] W. Chen, A. Al-Baz, J.M. Bishop and M. Al-Husaini. Field experiments to improve the efficacy of gargoor (fish trap) fishery in Kuwait,s waters. Chinese Journal of Oceanography and limnology, 2012; 30 (3): 535-546

[9] J.U. Lee, M. Samuel, F.Y. Al-Yamani and P.S. Joseph. Final report on fin fisheries Management Projevt, Phase IV. Kuwait Institute for Scientific Research, report No. KISR3484, Kuwait 1990.

[10] A. Al-Baz, J.M. Bishop, M. Al-Husaini and W. Chen. Gargoor trap fishery in Kuwait, catch rate and species composition. J. Appl. Ichthyol. 2018;34:867-877.

[11] M.J. Shabani, E. Camrani, M.Yahyavi, K.Khorshidian and R. Khodadadi. The effect of various trap (gargoor) mesh size on the catch fish composition and abundance in Bushehr province. Journal of Fisheries, Iranina Journal of natural Res., 2010. 63;3:97-110

[12] D. Robichaud, W. Hunte and H.A. Ocenford. Effects of increased mesh size on catch and fishing power of coral reef fish traps. Fisheries Research, 1999. 39: 275-294.

[13] R.J. Miller. How many traps should crab fishermen fish? North American Journal of Fisheries Management. 1983; 3: 1-8

[14] D.A. Somerton and M.F. Merritt. Method of adjusting crab per pot for differences in soak time and its application to Alaskan Tanner crab (Chionocetes bairdi) catches. North American Journal of Fisheries Management. 1986; 6:586-591

[15] S. Zhou and T.C. Shirley. A model expressing the relationship between catch and soak time for trap fisheries. North American Journal of Fisheries Management. 1997;17:482-487

[16] D. Pengilly and D. Tracy. Experemental effects of soak time on catch of legal-sized and nonlegal red king crabs by commercial king crab pots. Alaska fishery Bulletin. 1998;5;3:81-87 
[17] C.P. Mathews, V.R. Gouda, W.T. Riad and J. Dashti. Pilot study for the design of a long fish trap (Gargoor) for Kuwait,s fisheries. Kuwait Bulletin for marine Science. 1987;9:221-234

[18] H. Al-Masroori, H. Al-Oufi, J.L. Mcllwwain and E.McLean. Catches of lost fish traps (Ghost fishing) from fishing grounds near Muscat, Sultanate of Oman, Fisheries Research. 2004;69:407-414

AUTHORS

First Author -Elsayed Farrag, Ph.D. Fish Researcher, Ministry of Climate Change and Environment. eefarrag@moccae.gov.ae Second Author - Ahmed Al-Zaabi, Head of MERD, Ministry of Climate Change and Environment. amalzabi@moccae.gov.ae

Third Author - Romina L. Nuqui, Biologist, Ministry of Climate Change and Environment rlnuqui@moccae.gov.ae

Correspondence Author - Elsayed Farrag, eefarrag@ moccae.gov.ae, rlnuqui@moccae.gov.ae. contact number: 00971503028824 